\section{BMJ Global Health}

\title{
An analysis of International Health Regulations Emergency Committees and Public Health Emergency of International Concern Designations
}

\author{
Lucia Mullen, ${ }^{1,2}$ Christina Potter, ${ }^{1,2}$ Lawrence O Gostin, ${ }^{3}$ Anita Cicero, ${ }^{1,2}$ \\ Jennifer B Nuzzo ${ }^{1,2}$
}

To cite: Mullen L, Potter C, Gostin LO, et al. An analysis of International Health Regulations Emergency Committees and Public Health Emergency of International Concern Designations. BMJ Global Health 2020;5:e002502. doi:10.1136/ bmjgh-2020-002502

Handling editor Seye Abimbola

- Additional material is published online only. To view please visit the journal online (http://dx.doi.org/10.1136/ bmjgh-2020-002502).

Received 16 March 2020 Revised 15 May 2020 Accepted 18 May 2020

Check for updates

(c) Author(s) (or their employer(s)) 2020. Re-use permitted under CC BY-NC. No commercial re-use. See rights and permissions. Published by BMJ.

${ }^{1} J o h n s$ Hopkins Center for Health Security, Baltimore, Maryland, USA

${ }^{2}$ Department of Environmental Health \& Engineering, Johns Hopkins University Bloomberg School of Public Health, Baltimore, Maryland, USA ${ }^{3} 0$ 'Neill Institute for National \& Global Health Law, Georgetown Law, Washington, District of Columbia, USA

\section{Correspondence to}

Lucia Mullen; Imullen3@jhu.edu

\section{ABSTRACT}

Introduction Nine events have been assessed for potential declaration of a Public Health Emergency of International Concern (PHEIC). A PHEIC is defined as an extraordinary event that constitutes a public health risk to other states through international spread and requires a coordinated international response. The WHO DirectorGeneral convenes Emergency Committees (ECs) to provide their advice on whether an event constitutes a PHEIC. The EC rationales have been criticised for being nontransparent and contradictory to the International Health Regulations (IHR). This first comprehensive analysis of EC rationale provides recommendations to increase clarity of EC decisions which will strengthen the IHR and WHO's legitimacy in future outbreaks.

Methods 66 EC statements were reviewed from nine public health outbreaks of influenza A, Middle East respiratory syndrome coronavirus, polio, Ebola virus disease, Zika, yellow fever and coronavirus disease-2019. Statements were analysed to determine which of the three IHR criteria were noted as contributing towards the EC's justification on whether to declare a PHEIC and what language was used to explain the decision.

Results Interpretation of the criteria were often vague and applied inconsistently. ECs often failed to describe and justify which criteria had been satisfied.

Discussion Guidelines must be developed for the standardised interpretation of IHR core criteria. The ECs must clearly identify and justify which criteria have contributed to their rationale for or against PHEIC declaration.

Conclusion Striving for more consistency and transparency in EC justifications would benefit future deliberations and provide more understanding and support for the process.

\section{INTRODUCTION}

In the aftermath of severe acute respiratory syndrome (SARS) outbreak, the WHO fundamentally revised the International Health Regulations (IHR), which entered into force in 2007. The 196 States Parties to the IHR recognised that certain public

\section{Key questions}

What is already known?

- There has been increasing criticism over Public Health Emergency of International Concern (PHEIC) declarations and non-declarations by public health and international law experts.

- Critics have claimed that the rationale used by Emergency Committees (ECs) to recommend or not recommend a PHEIC to the WHO Director-General can be contradictory, non-transparent and, in some cases, in direct violation of the criteria as defined by the International Health Regulations (IHR).

\section{What are the new findings?}

- We conducted the first, comprehensive, formal review and analysis of official statements published on behalf of ECs by the WHO to definitively identify the rationale reported for declaring or not declaring a PHEIC and analyse how that rationale matches with criteria set forth by the IHR.

- There was considerable inconsistency and application of the criteria for a PHEIC as defined by the IHR.

What do the new findings imply?

- A more standardised and transparent process for ECs is needed to assess the event and determine if a PHEIC declaration is warranted for the public health community to understand the decision-making process.

- Guidelines that include the standardised definitions and how they should be assessed for each of the three core IHR criteria is necessary for future PHEIC declarations to ensure confidence in the IHR EC process remains.

health events pose a significant risk to the global community and should be designated as a Public Health Emergency of International Concern (PHEIC). Under Article I of the IHR, a PHEIC is defined by three criteria: an extraordinary event which "constitute[s] a public health risk to other States through international spread of 
disease and...potentially require $[\mathrm{s}]$ a coordinated international response.' The IHR (Annex 2) provides a 'decision instrument' that guides States Parties as to which health events have the potential to become PHEICs, thus requiring reporting to WHO. [Annex 2 of the IHR provides a decision instrument for States Parties to assess which events detected by national surveillance systems would require notification to the WHO. This includes a single case of smallpox, poliomyelitis due to wild-type poliovirus, human influenza caused by a new subtype and SARS. Other health events that have the potential to cause international public health concerns or serious impact trigger an algorithm to determine if notification to WHO is required. Criteria for this algorithm include determining if the event is serious, unusual or unexpected, has a significant risk of international spread, or poses a significant risk of international travel or trade restrictions. If two of the criteria are true, then notification to WHO is required under the IHR]. The IHR also empowers the WHO Director-General (DG) to convene an Emergency Committee (EC) which consists of international experts brought together on an ad-hoc basis. The EC provides their advice on whether the current situation should be considered a PHEIC, and what Temporary Recommendations should be given to Member States to bolster the response and control the outbreak. Ultimately, however, the WHO DG has sole authority to declare a PHEIC and make Temporary Recommendations for Member States to follow. ${ }^{1}$

The WHO's decision-making under the IHR has come under intense scrutiny, especially its decision whether to declare a PHEIC. Global commissions, for example, strongly criticised the organisation for waiting 4 months after international spread of Ebola virus disease (EVD) in West Africa (2014-2016) before declaring an emergency. ${ }^{2}$ During the ongoing EVD outbreak in the Democratic Republic of Congo (DRC), the EC met a total of six times but did not declare a PHEIC until the fourth convocation, more than 11 months after the outbreak began. ${ }^{34}$ Most recently, the WHO's judgement in response to coronavirus disease-2019 (COVID-19) has been questioned. The WHO DG first convened the EC on January 22, but announced it had insufficient data from China to arrive at a decision. The following day, the EC was almost equally divided, but ultimately said it was too early to declare a PHEIC. Seven days later, on 30 January 2020 during the second EC meeting, the DG declared a PHEIC. The WHO DG openly stated that the IHR should be reformed to allow intermediate levels for declaring an emergency, suggesting that an all or nothing standard hindered EC decision-making. ${ }^{35}$

Experts have urged WHO to clarify how decisions should be reached, ${ }^{6-8}$ as well as proposing greater transparency in the EC decision-making process to better understand why the Committee recommended or did not recommend a PHEIC declaration. ${ }^{9}$ Overall, the IHR EC decision-making process is open to considerable interpretation. ${ }^{10}$ In addition, the WHO DG has raised concerns about the negative impacts that PHEIC declarations may trigger, especially travel and trade restrictions. ${ }^{35}$

To date, there has yet to be a comprehensive analysis of EC recommendations and WHO DG decision-making regarding PHEIC declarations. To describe how the EC and the WHO DG relied on and interpreted these criteria in previous decisions to declare or not to declare PHEICs, we examined the EC's decision-making in all instances where it has met from when the revised IHR entered into force in 2007. We summarised and categorised the justifications offered by the EC, identified the criteria used in each situation and compared these to criteria for PHEICs outlined by the IHR. Based on this analysis, we offer important recommendations for increasing transparency and consistency in EC recommendations and PHEIC decision-making. Adoption of these regulations would strengthen IHR decision-making and WHO legitimacy in responding to major outbreaks.

\section{METHODS}

We searched the WHO's website for all instances where the WHO DG convened an EC from when the revised IHR entered into force in 2007. During this review, we identified a total of nine public health events for which ECs were convened: the influenza A (H1N1) pandemic (2009-2010), the Middle East respiratory syndrome coronavirus (MERS-CoV) outbreak (2013-2015), the international spread of poliovirus (2014-ongoing), the West Africa EVD outbreak (2014-2016), the Zika virus outbreak (2016), yellow fever (2016), the 9th EVD outbreak in the Equateur province of DRC (2018), the 10th EVD outbreak in DRC which began in the North Kivu and Ituri provinces (2018-ongoing) and the on-going epidemic of COVID-19. We identified the number of EC meetings that were convened for each health event and collected the official statements detailing the WHO DG's decision and the EC's justification. While EC meetings were often followed by a press conference where the WHO DG and the chair of the EC reported on their internal discussions and ultimate decision as well as answered questions from journalists, it was decided that these discussions would not be included in the scope of this study. For each of the aforementioned health events, we also identified and recorded epidemiological characteristics of the outbreaks including date of detection, date of initial EC meeting, number of countries affected prior to initial EC meeting as well as the total number of countries affected, and the average case fatality rate reported over the course of the outbreak.

There were a total of $66 \mathrm{EC}$ meetings for review (H1N1 $(\mathrm{n}=9)$, MERS-CoV $(\mathrm{n}=10)$, polio $(\mathrm{n}=22)$, West Africa EVD $(n=9)$, Zika $(n=5)$, yellow fever $(n=2)$, ninth EVD in DRC $(n=1)$, 10th EVD in DRC $(n=6)$, COVID-19 $(\mathrm{n}=2)) .{ }^{34}$ Each EC statement was analysed to determine which of the three fundamental IHR criteria were noted as contributing towards the EC's justification on whether to declare a PHEIC, and specifically, what language was 
used by the EC to explain their decision-making process. [In accordance with the definition of a PHEIC outlined in the IHR, the three fundamental criteria we searched for included whether the situation constituted an extraordinary event, if there was a 'public health risk to other States via international spread', and whether a coordinated international response was required.] In addition, we identified and recorded other thematic factors that contributed either to the determination of the three essential IHR criteria or overall decision to declare a PHEIC. These factors included: sustained community transmission, gaps in knowledge of the agent or limited response experience, impending mass gatherings, threat to eradication and complex response settings.

\section{Patient and public involvement}

Patients and the public were not involved in this study.

\section{RESULTS}

Of the nine events analysed, PHEICs were declared in six instances: H1N1 in 2009, Poliovirus in 2014, West Africa EVD outbreak in 2014, Zika outbreak in 2016, the 10th DRC EVD outbreak in North Kivu and Ituri provinces in 2019, and the ongoing COVID-19 outbreak (table 1). ${ }^{34}$ Detailed information on each EC meeting and the criteria identified as contributing to the rationale of EC justifications can be found in online supplementary file 1 .

\section{H1N1 pandemic}

Approximately 1 month after initial cases were detected, the first EC was convened and a PHEIC declared. The EC indicated that all three conditions for a PHEIC had been met: the event was considered extraordinary, there was a public health risk to other States via international spread, and an international response was required to control the outbreak. The EC met a total of nine times throughout the pandemic but did not recommend the PHEIC be declared over until 10 August 2010 as it 'no longer represented an extraordinary event,' the 'world was no longer experiencing an influenza pandemic,' and the response did not require 'immediate emergency actions on an international scale'.

\section{Middle East respiratory syndrome coronavirus}

While regular notifications of MERS-CoV cases were reported to WHO for 2012-2013, approximately 10 months following the initial notification on 22 September 2012, the WHO DG convened the EC to independently offer an expert review of the situation regarding this novel virus. At the first meeting on 9 July 2013, the EC determined that more information was needed, and further time was warranted for deliberation, therefore it was agreed that the Committee would meet in 8 days to provide a decision. The EC met a total of 10 times between 9 July 2013 and 2 September 2015 and a PHEIC was not declared at any point. ${ }^{3}$ Numerous countries reported MERS-CoV cases, thus indicating there was a public health risk to other countries through international spread. ${ }^{11} 12$
In 2015, South Korea reported 186 laboratory-confirmed cases and 38 deaths, the largest outbreak outside of the Middle East. ${ }^{13}$ That same year, on 2 September 2015, the EC noted that ' $[p]$ rogress is not yet sufficient to control this threat and until this is achieved, individual countries and the global community will remain at significant risk for further outbreaks.' Despite being a novel virus, the EC did not consider the MERS-CoV outbreaks to be an extraordinary event. While the EC did not explicitly state that a coordinated international response was required, in their final meeting they noted that 'sectors must collaborate, among themselves and internationally,' implying a coordinated international response was necessary. ${ }^{3}$

\section{Polio}

The first EC meeting, on 28-29 April 2014, was convened to discuss the international spread of wild poliovirus in 2014 and its threat to the global polio eradication initiative. The difference between the low transmission rates for poliovirus in 2012 and early 2013 compared to a rapid increase in transmission rates in late 2013 and into 2014 brought concern that eradication efforts were at risk. The Committee reported all conditions for a PHEIC were met. Since 28 April 2014, the EC convened an additional 21 times and deemed the PHEIC declaration should continue as the risk of international spread and need for a coordinated international response remained. The Committee also argued that the extraordinary context of being close to polio eradication and the concern of complacency threatening the eradication efforts support the argument to continue the PHEIC declaration. ${ }^{3}$

\section{West Africa EVD}

The WHO published the official notification of the outbreak on 23 March 2014. ${ }^{14}$ The first EC was convened over 4 months later on 6-7 August 2014 after cases had been reported from Guinea, Liberia, Nigeria and Sierra Leone. The Committee determined the outbreak constituted an extraordinary event, posed a public health risk to other States through international spread, and required a coordinated international response to control the virus, therefore concluding the "conditions for a (PHEIC) have been met. ${ }^{3}$

\section{Zika virus}

Two months after the Pan American Health Organization and WHO published an epidemiological alert regarding an increase in neurological disorders in areas where Zika was reported, ${ }^{15}$ on 1 February 2016 the EC was convened to deliberate on whether a PHEIC was constituted. ${ }^{3}$ While 25 countries in the Americas had reported cases of Zika, ${ }^{1617}$ there was no mention of the public health risk to other States through international spread in the initial meeting where a PHEIC was declared. The Committee also did not note whether a coordinated international response was required. There was no mention in this meeting that the event was considered extraordinary. However, language from a later EC meeting on 18 


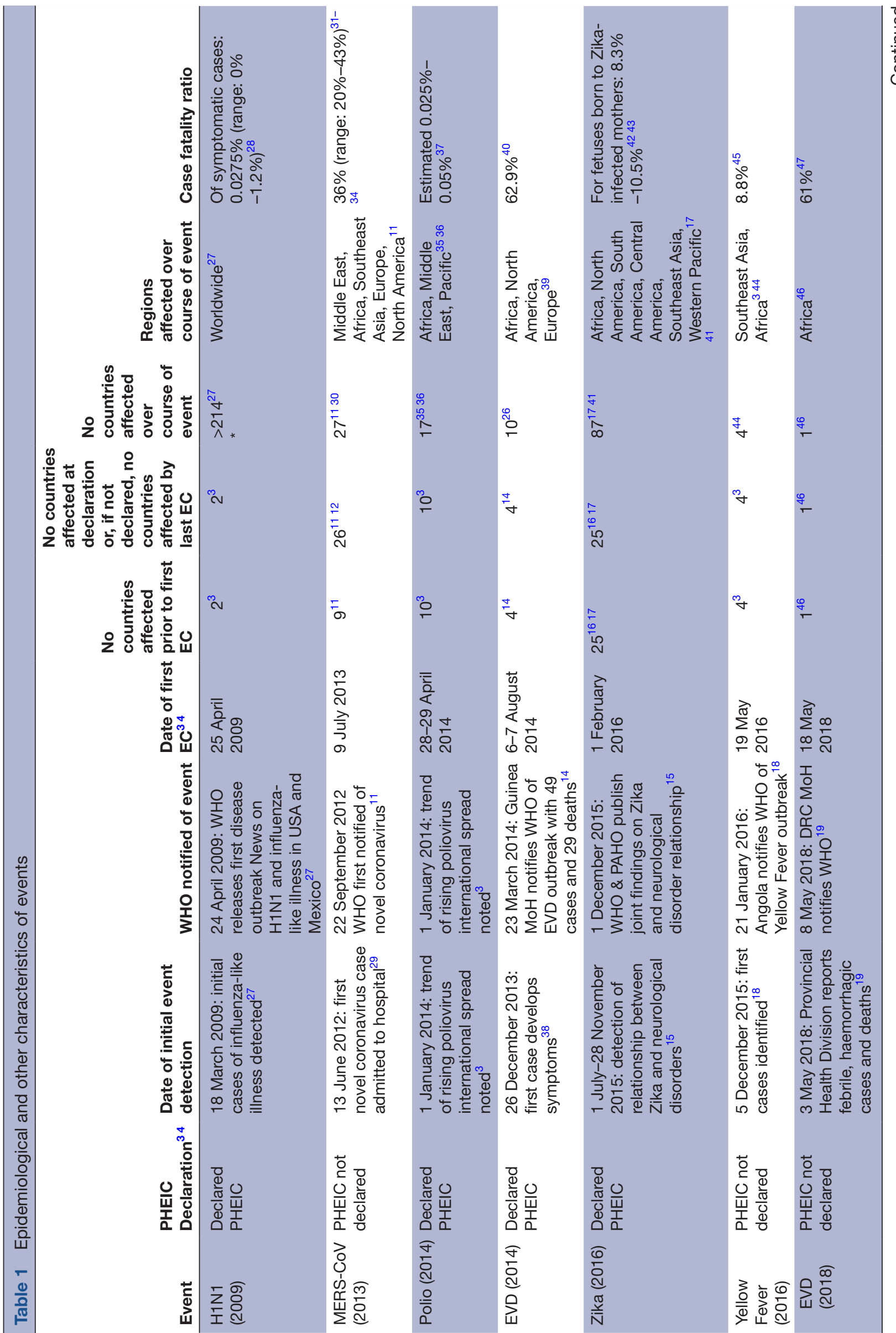



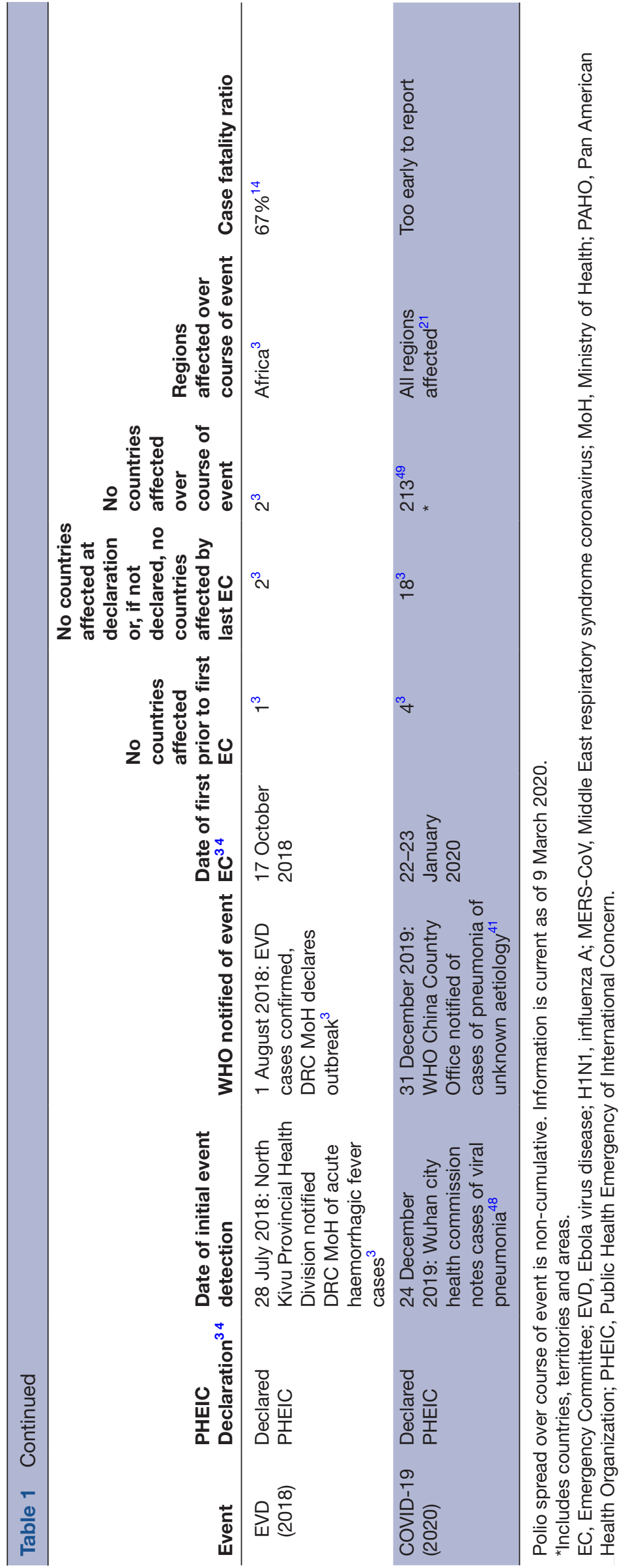
November 2016 indicated that the unknown, apparent association between Zika and neurological disorders was considered an extraordinary event. [The EC did not determine that Zika itself was a PHEIC, but rather the report of Zika cases with the additional concern of neurological disorders constituted a PHEIC]. The EC met a total of five times from February 2016 to 18 November 2016 and noted the gaps in knowledge of the virus and its consequences. ${ }^{3}$

\section{Yellow fever}

Four months after notification of yellow fever cases in Angola ${ }^{18}$ the WHO DG convened an EC on 19 May 2016. There was international spread of yellow fever to DRC, China and Kenya, and the Committee noted the international risk posed by the outbreak. It also called for international support for the response. Yet, the EC determined the event did not constitute a PHEIC. The Committee met a second time on 31 August 2016 and reported similar findings. During both meetings, the Committee made no note on whether the outbreak was considered an extraordinary event. ${ }^{3}$

\section{EVD DRC (Equateur)}

The ninth EVD outbreak of DRC was declared by its Ministry of Health on 8 May 2018 in the Equateur province $^{19}$ and 10 days later the WHO DG convened the EC. The Committee reported that the conditions for a PHEIC had not been met. While the Committee noted that the public health risk of international spread was high, they considered that the robust, coordinated response by the DRC government, WHO and partners and 'the interventions underway provide[d] strong reason to believe that the outbreak can be brought under control.' The Committee also noted that there was no actual international spread, which appeared to impact their decision not to declare a PHEIC as they noted '[i]f the outbreak expands significantly, or if there is international spread, the Emergency Committee will be reconvened.' The Committee made no mention on whether the event was considered extraordinary. Due to the brevity of the outbreak, only one EC meeting was convened. ${ }^{3}$

\section{EVD DRC (North Kivu and Ituri)}

On 17 October 2018 the WHO DG convened the first EC for DRC's 10th EVD outbreak, centred in the North Kivu and Ituri provinces. A PHEIC was not declared until the fourth EC meeting on 17 July 2019. The Committee expressed in multiple meetings that a PHEIC declaration may be detrimental to the ongoing response. For example, in the second EC meeting, the Committee noted 'there is no added benefit to declaring a PHEIC at this stage,' and in the third EC meeting, '[t] he Committee extensively debated the impact of a PHEIC declaration on the response, possible unintended consequences, and how these might be managed.' During the first two meetings, while the EC reported that while there was a high risk of spread at the national and regional levels, it did not think that transnational spread beyond bordering countries was likely. The Committee gave no indication as to whether the noted risk of regional spread met the IHR criterion of a "public health risk to other States through international spread'. However, during the third EC meeting on 14 June 2019 the Committee 'acknowledged that recent cases in Uganda constitute international spread of disease' and considered the outbreak had a risk of international spread. The Committee called for the DRC government, WHO, and partners to intensify the response to ensure the situation did not deteriorate during earlier meetings, but it did not specifically state a coordinated international response was needed until the fourth meeting. During the third EC, the Committee explicitly reported the event as extraordinary, acknowledged the risk of the disease spreading to neighbouring countries-as cases had been reported in Ugandaand called for the international community to step up funding and support' for the response. However, the EC still stated that the outbreak '[did] not meet all the three criteria for a PHEIC' at the time. ${ }^{1}$ It was not until the following meeting when the Committee stated '[i]t was the view of the Committee that a coordinated international response under the International Health Regulations (2005) is required. Thus, the conditions for a Public Health Emergency of International Concern (PHEIC) under the IHR (2005) have been met. ${ }^{3}$ The EC has met an additional two times and advised for a continuation of a PHEIC declaration as " $\mathrm{t}$ ] he Committee was concerned that withdrawing the PHEIC now might have adverse consequences for the response efforts through diminishing focus. ${ }^{34}$

\section{Coronavirus disease-2019}

China notified WHO of a cluster of pneumonia cases with unknown aetiology on 31 December $2019,{ }^{20}$ and the WHO DG convened the EC approximately 3 weeks later on 22-23 January 2020. At the time, 557 cases were reported, and four countries confirmed exported (travelrelated) cases from China. Similar to previous EC meetings for MERS, polio and West Africa Ebola, the first EC meeting for novel coronavirus did not reach a decision on the first day of meeting, but continued its deliberations on the next day due to the need for additional information and deliberation. In the EC statement, the Committee noted that 'it is expected that further international exportation of cases may appear in any country,' implying an ongoing public health risk to other States via international spread. While it was reported that 'members of the Emergency Committee expressed divergent views on whether this event constitutes a PHEIC or not,' ultimately a PHEIC was not declared at the end of 23 January. As seen with MERS-CoV, the WHO DG suggested the EC reconvene in a matter of days to reassess the evolving situation and provide an updated determination on whether the event constitutes a PHEIC. The EC met again on 30 January 2020, when there were 7711 confirmed cases in China and an additional 83 reported 


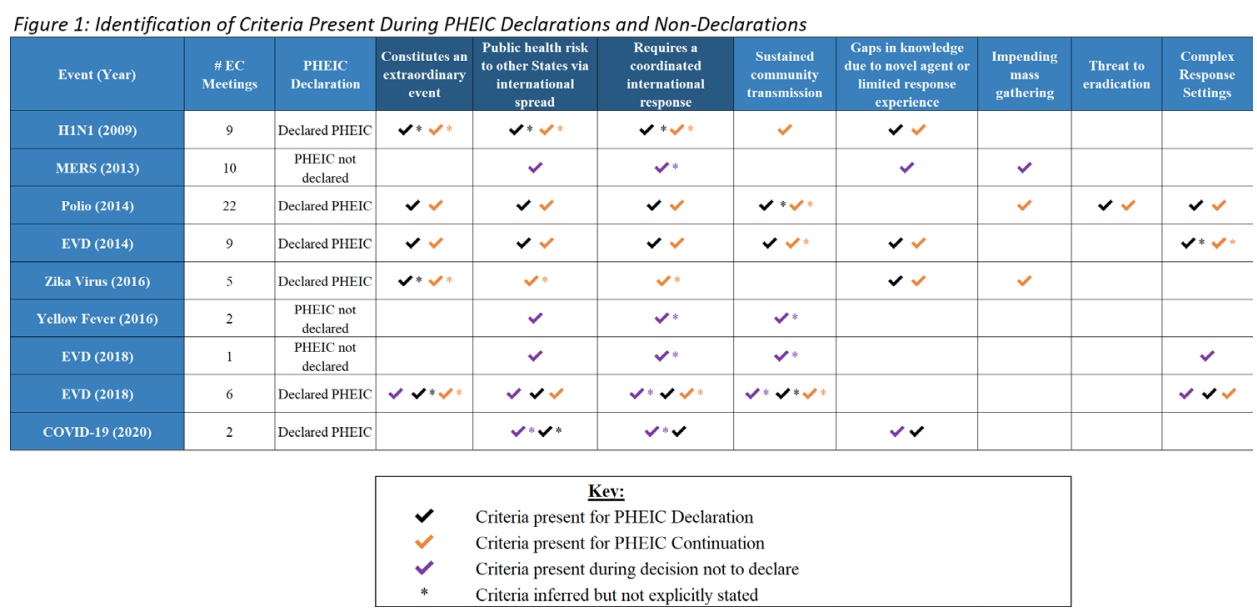

Figure 1 Outlines which criteria and thematic factors were explicitly stated or implied as contributing to the Emergency Committee recommendation to the WHO Director-General. COVID-19, coronavirus disease-2019; EVD, Ebola virus disease; H1N1, influenza A; MERS, Middle East respiratory syndrome; PHEIC, Public Health Emergency of International Concern.

cases in 18 other countries, at which time the EC 'agreed that the outbreak now meets the criteria for a Public Health Emergency of International Concern.' The EC reiterated its language from the prior meeting regarding risk of importation, indicating an ongoing public health risk to other States via international spread. Additionally, the EC stated in the second meeting that they 'felt that a global coordinated effort is needed.' Neither the first nor second EC meeting noted whether or not the event was considered extraordinary. ${ }^{3}$ At the time of writing, COVID-19 was reported in countries on six continents, spreading rapidly including through community transmission. ${ }^{21}$

\section{DISCUSSION}

Figure $1^{34}$ outlines which criteria and thematic factors were explicitly stated or implied as contributing to the EC recommendation to the WHO DG.

We find considerable inconsistency in statements issued by the EC regarding their determination of whether the IHR criteria for a PHEIC have been met. The ECs did not always require each of the three conditions to be met in order to recommend that a PHEIC should be declared. During the first Zika EC meeting when a PHEIC was recommended, there was no explicit mention of a risk of international spread nor did the EC state that a coordinated, international response was required. In contrast, the EC determined the yellow fever outbreaks in 2016 did not constitute a PHEIC even though they stated the outbreaks posed a public health risk to other States through international spread and indicated that enhanced international support was needed. ${ }^{3}$

When the ECs did reference specific PHEIC criteria, they were often inconsistent in their interpretation of whether the criteria were met. For example, for some events (H1N1, polio and the West Africa EVD outbreak) ECs interpreted the criterion of 'requiring a coordinated international response' to mean that the event required such coordination, but did necessitate that on-going coordination be enhanced or improved in order for the criterion to be met. In contrast, for the ninth DRC EVD outbreak, the EC argued that while the 'response should be supported by the entire international community' implying the need for a coordinated international response, a PHEIC was not necessary because the existing response was 'rapid and comprehensive' and there was reason to believe the outbreak could be brought under control. Similarly, for the 10th DRC EVD outbreak, in earlier meetings, the Committee noted ' $\mathrm{t}] \mathrm{h}$ he government of the Democratic Republic of Congo, WHO, and partners must intensify the current response' indicating a coordinated international response was underway; however, the EC did not acknowledge that the criterion of a coordinated international response was met until the forth EC meeting on 17 July $2019 .{ }^{3}$

The criterion for determining if an event is considered extraordinary was also interpreted inconsistently. For both H1N1 and Zika, insufficient knowledge about the virus was cited as a factor in these situations being deemed extraordinary events. In contrast, the EC s never stated that MERS-CoV and COVID-19 (both outbreaks resulting from novel viruses for which there were significant gaps in knowledge of disease aetiology) constituted an extraordinary event. ${ }^{3}$

ECs varied in their interpretation of and the supporting evidence used to assess the criterion of there being a risk of international spread. The EC was inconsistent in whether it required that international spread to have already occurred vs there simply being risk that spread could occur in order for this criterion to be met. In some cases (H1N1, polio, West Africa EVD, yellow fever, ninth DRC EVD outbreak, 10th DRC EVD outbreak), the EC noted the threat of international spread when a disease involved sustained human-to-human or community transmission. However, despite the absence of sustained human-to-human transmission, the EC considered MERS-CoV outbreak to have a risk of international spread stating 'the possibility of international spread 
remains of concern' on 4 February 2015. For polio, an impending mass gathering, the Hajj, was used as rationale to continue a PHEIC declaration due to the risk it posed for international spread. However, for MERS-CoV, the EC did not note that they considered the Hajj a factor that contributed to the risk of international spread. The upcoming Olympics were also acknowledged during Zika EC meetings and it was recognised that mass gatherings can pose additional risks to international spread. It was ultimately deemed that with proper public health control measures, the risk of the Olympics contributing to international spread was negligible, and therefore, not factored into this criterion. ${ }^{3}$

By design, this study only reviewed the official statements of EC meetings to identify and analyse the rationale provided and determine if PHEIC criteria were present or absent. Most, but not all, EC meetings were followed by a press conference where the DG and the chair of the EC provided a verbal report of the meeting and answer questions posed by journalists. While these press conferences often allowed for further clarification of the EC decision, whether or not additional, clarifying information was relayed at press conferences was often contingent on the types of questions that happened to be asked by member of the press. As a result, these conferences cannot be viewed as a replacement for EC reports as a vehicle for explaining the rationale used by the EC in deciding whether an event met each of IHR criteria for a PHEIC declaration. To ensure there is complete understanding of the analysis and decision-making of the EC, the official reports of the EC should contain all of the necessary information regarding which IHR criteria were determined to have been. Transparency in this IHR process must be prioritised and, therefore, the official EC statements must provide a clear indication of how each of the three IHR criteria were deemed to have been met and include all the relevant information necessary to justify the decision to recommend declaration (or not) of a PHEIC.

Lack of consistency and clarity regarding the EC and the WHO DG's decision-making contributes to ongoing concerns about a lack of transparency in the PHEIC process and other public disagreements with PHEIC declarations. ${ }^{9}$ Though ECs may have discussed each outbreak with greater clarity and consistency than what was publicly reported, it is important that the public representation of the EC's rationale be fully articulated so that Member States and outside observers have a full record of the EC's decision-making process. Lack of transparency surrounding the EC process has been a continuous point of contention for public health experts who noted the original reticence of WHO to disclose the identity of EC members following the H1N1 EC deliberations. ${ }^{22}$

Similarly, it is important that the EC's recommendations are seen as consistent with the expectations of the IHR.

We recommend that in future convenings, the EC standardise their reviews of events to specifically address whether the event met each of the three criteria and to list corresponding evidence to support the presence/ absence of each criterion. In addition, the EC should offer detailed explanation of how they interpreted the criteria. In order to standardise the EC review process and ensure explanations are provided to clearly justify decisions on PHEIC declarations and non-declarations, EC members should undergo further training regarding the authorities and decision-making criteria established by the IHR, a sentiment that is shared by other public health and international law experts. ${ }^{22}$ Notably, global health law experts have not been part of the composition of ECs. ${ }^{34}$ Adding legal expertise to future EC deliberations will help to resolve confusion about the IHR criteria and promote consistency with previous decisions.

Going forward, the WHO should, in consultation with member states and legal experts, develop clear guidelines to aid ECs in interpreting PHEIC criteria. In particular, there seems to be confusion among EC members as to whether the 'risk of international spread' criterion has to involve documented international spread. The IHRs do not specify that international spread must have already occurred and it would likely be against the spirit of the IHRs, which aim to reduce international spread of infectious diseases, for the ECs to need to wait until international spread has occurred in order to declare a PHEIC. ${ }^{1}$

The makeup of the EC is ill-equipped to address political and social considerations. While these considerations are important and relevant factors to take into account when responding to an outbreak, the IHR does not provide the ECs with the authority to consider the political and social implications. The ECs should disavow including these concerns in their deliberations and ensure that they only consider the available technical evidence on whether the three core criteria have or have not been met when determining if the event constitutes a PHEIC. Other avenues should be used to account for the political and social considerations as they are a necessary component of ensuring a robust and successful response to a health emergency. Box 1 provides a summary of the recommendations outlined in this paper.

With more consistency and transparency in EC justifications, there could be a better understanding on how the EC and the WHO DG reach their decision on whether an event should be considered a PHEIC. Similarly, as previous PHEIC determinations are often reviewed to compare the decision-making processes between public health events, a more structured approach should be provided that explicitly states what criteria were met and how the EC determined that each criterion was satisfied. This approach will remove some ambiguity and enable the international community to gain further insight into the EC's thought process and their recommendations on whether to declare a PHEIC.

It is essential for PHEIC declarations to be made based on science, not politics. In recent convenings, ECs have seemed reluctant to recommend a PHEIC declaration, noting the potential for countries to respond with trade 


\section{Box 1 Summary of recommendations}

1. Emergency Committees (ECs) should standardise their review of an outbreak to specifically address whether the event met each of the criteria for a Public Health Emergency of International Concern (PHEIC); the outbreak should constitute as an extraordinary event, be a public health risk to other Member States though international spread of disease, and require a coordinated, international response.

2. WHO should include global health law experts in the composition of future EC meetings to ensure proper legal advice on the International Health Regulations criteria can be shared with EC members and properly applied during the decision-making process.

3. WHO, Member States and legal experts should develop clear guidelines to aid ECs in interpreting PHEIC criteria.

4. ECs should only consider the available technical evidence of events when determine if criteria for a PHEIC are met rather than incorporating additional considerations in the deliberations such as the political implications.

5. The EC should endeavour to provide clear and consistent statements outlining the decision-making process for PHEIC declarations. This would include a standardised statement reviewing their discussions and listing evidence to support their determination of the presence or absence of each PHEIC criterion.

and travel measures that could harm response to the health event. ${ }^{323}$ Though concerns that countries may pursue harmful measures to stop the importation of disease are legitimate, ${ }^{24}$ the decision-making process established by the IHR does not accommodate these political considerations. ${ }^{1}$ The ECs should review the potential public health impact of the event and limit their decision-making to a technical assessment of each event. The WHO should address separately, outside of the PHEIC declaration process, the problem of Member States taking actions that are inconsistent with WHO recommendations and place unnecessary travel and trade restrictions on affected countries, which would be detrimental to both the country and the response efforts.

PHEIC declarations are not the entire focus of the IHR. The Regulations also require countries to develop capacities to detect and report potential PHEICs. ${ }^{1}$ If there is a lack of understanding of the rationale that EC uses to recommend PHEIC declarations, or if PHEIC declarations are seen to be political, it could undermine confidence in the IHR. Though the IHR are instruments of law, their impact depends on countries' willingness to comply. It is essential for future compliance with the IHR that the WHO, ECs and Member States interpret the framework as written. If the Regulations are thought to be inadequate in supporting assessment and response to international public health emergencies, then a revision of the IHR may be necessary. Following the EC's recommendation to declare the on-going COVID-19 epidemic a PHEIC, the WHO DG expressed frustration with the binary decision-making set up by the IHRs and suggested that a tiered decision-making tool, with an intermediary measure, may be more useful to gauge the level of emergency posed by health events. ${ }^{3}$ Such a suggestion would likely require a revision of the IHR, as the decision instrument contained in Annex 2 does not accommodate a multi-phase declaration.

\section{CONCLUSION}

This first comprehensive review of EC statements found considerable inconsistency in the justifications dictating which criteria were considered to be met and how the criteria were considered to be satisfied. Recently debates about the value and timing of PHEIC declarations have also called into question the benefit and impact of PHEIC declarations. ${ }^{2526}$ Some of these concerns may stem from lack of understanding of EC's rationale and EC's lack of agreement and/or understanding of PHEIC criteria set forth by the IHR. Striving for more consistency and transparency in the EC justifications around PHEIC declarations would benefit future deliberations and help to build more understanding and support for the process.

Twitter Lucia Mullen @LuciaMullen17

Acknowledgements We would like to thank Brianna Saunders for her initial analysis of the International Health Regulations Emergency Committee meetings.

Contributors LM and CP led the data collection and analysis. JBN oversaw the research project. LM led the drafting of the manuscript and CP, LOG, AC and JBN contributed.

Funding Funding was generously provided by the Open Philanthropy Project.

Competing interests None declared.

Patient and public involvement Patients and/or the public were not involved in the design, or conduct, or reporting, or dissemination plans of this research.

Patient consent for publication Not required.

Provenance and peer review Not commissioned; externally peer reviewed.

Data availability statement Data sharing not applicable as no datasets generated and/or analysed for this study. Data was gathered from qualitative analysis of publicly available statements from the International Health Regulations Emergency Committees, found on the World Health Organization website.

Open access This is an open access article distributed in accordance with the Creative Commons Attribution Non Commercial (CC BY-NC 4.0) license, which permits others to distribute, remix, adapt, build upon this work non-commercially, and license their derivative works on different terms, provided the original work is properly cited, appropriate credit is given, any changes made indicated, and the use is non-commercial. See: http://creativecommons.org/licenses/by-nc/4.0/.

\section{REFERENCES}

1 World Health Organization. International health regulations. 3 edn World Health Organization, 2016.

2 Gostin LO, Tomori O, Wibulpolprasert S, et al. Toward a common secure future: four global commissions in the wake of Ebola. PLoS Med 2016;13:e1002042.

3 World Health Organization. International health regulations committees and expert roster. Available: http://www.who.int/ihr/ procedures/ihr_committees/en/

4 World Health Organization. Statement on the meeting of the international health regulations (2005) emergency committee for Ebola virus disease in the Democratic Republic of the Congo on 12 February 2020. Available: https://www.who.int/news-room/detail/ 12-02-2020-statement-on-the-meeting-of-the-international-healthregulations-(2005)-emergency-committee-for-ebola-virus-diseasein-the-democratic-republic-of-the-congo-on-12-february-2020

5 Joseph A. WHO declares coronavirus outbreak a global health emergency. STAT, 2020.

6 The Lancet. The politics of PHEIC. Lancet 2019;393:2470.

7 Zarocostas J. Ebola outbreak not a PHEIC, says WHO. Lancet 2019;393:2479. 
8 Gostin L, Phelan A, Coutinho AG, et al. Ebola in the Democratic Republic of the Congo: time to sound a global alert? Lancet 2019;393:617-20.

9 Eccleston-Turner M, Kamradt-Scott A. Transparency in IHR emergency committee decision making: the case for reform. BMJ Glob Health 2019;4:e001618.

10 Science Media Centre. Expert reaction to WHO decision not to declare the China coronavirus outbreak a PHEIC (public health emergency of international concern. Science Media Centre, 2020.

11 World Health Organization. MERS-CoV: disease outbreak news, 2019. Available: http://www.who.int/csr/don/archive/disease/ coronavirus infections/en/

12 World Health Organization. Middle East respiratory syndrome coronavirus (MERS-CoV) maps and epicurves, 2015. Available: https://www.who.int/csr/disease/coronavirus infections/mapsepicurves-7-13-september/en/

13 Ki M. 2015 MERS outbreak in Korea: hospital-to-hospita transmission. Epidemiol Health 2015;37:e2015033-e33.

14 World Health Organization. Ebola virus disease: disease outbreak news, 2020. Available: http://www.who.int/csr/don/archive/disease/ ebola/en/

15 Pan American Health Organization, World Health Organization. Epidemiological alert. neurological syndrome, congenital malformations, and Zika virus infection. Implications for public health in the Americas, 2015. Available: http://www.paho.org/hq/ index.php?option=com_docman\&task=doc_view\&ltemid=270\&gid= 32405\&lang=en

16 World Health Organization. Zika situation report. World Health Organization, 2017.

17 World Health Organization. Zika virus infection: disease outbreak news, 2019. Available: http://www.who.int/csr/don/archive/disease/ zika-virus-infection/en/

18 World Health Organization. Yellow Fever - Angola, 2016. Available: http://www.who.int/csr/don/12-february-2016-yellow-fever-angola/ en/

19 Barry A, Ahuka-Mundeke S, Ali Ahmed Y, et al. Outbreak of Ebola virus disease in the democratic republic of the Congo, april-may, 2018: an epidemiological study. Lancet 2018;392:213-21.

20 World Health Organization. Pneumonia of unknown cause - China, 2020. Available: http://www.who.int/csr/don/05-january-2020pneumonia-of-unkown-cause-china/en/

21 World Health Organization. Novel coronavirus (COVID-19) situation. World Health Organization, 2020. http://who.maps.arcgis.com/apps/ opsdashboard/index.html\#/c88e37cfc43b4ed3baf977d77e4a0667

22 Kamradt-Scott A. The International health regulations (2005). Int Organ Law Rev 2019;16:242-71.

23 Giesecke J, Bedford J, Enria D, STAG-IH. The truth about PHEICs. Lancet 2019. doi:10.1016/S0140-6736(19)31566-1. [Epub ahead of print: 05 Jul 2019].

24 Worsnop C. Provoking barriers: the 2014 Ebola outbreak and unintended consequences of who's power to declare a public health emergency. Global Health Gov 2017;11:7-26.

25 Zarocostas J. Ebola outbreak declared a PHEIC, world waits for next steps. Lancet 2019;394:287-8.

26 Hoffman SJ, Silverberg SL. Delays in global disease outbreak responses: lessons from H1N1, Ebola, and Zika. Am J Public Health 2018;108:329-33.

27 World Health Organization. Situation updates - pandemic (H1N1) 2009, 2010. Available: http://www.who.int/csr/disease/swineflu/ updates/en/
28 Wong JY, Kelly H, Ip DKM, et al. Case fatality risk of influenza A (H1N1pdm09): a systematic review. Epidemiology 2013;24:830-41.

29 Zaki AM, van Boheemen S, Bestebroer TM, et al. Isolation of a novel coronavirus from a man with pneumonia in Saudi Arabia. N Engl J Med 2012;367:1814-20.

30 World Health Organization. Middle East respiratory syndrome, 2020. Available: http://www.emro.who.int/health-topics/mers-cov/mersoutbreaks.htm

31 World Health Organization. WHO MERS-CoV global summary and assessment of risk. World Health Organization, 2019.

32 Oh M-D, Park WB, Park S-W, M-D O, Park S-W, et al. Middle East respiratory syndrome: what we learned from the 2015 outbreak in the Republic of Korea. Korean J Intern Med 2018;33:233-46.

33 Hajjar SA, Memish ZA, Mclntosh K. Middle East respiratory syndrome coronavirus (MERS-CoV): a perpetual challenge. Ann Saudi Med 2013;33:427-36.

34 The Lancet Infectious Diseases. MERS--an uncertain future. Lancet Infect Dis 2015;15:1115.

35 Global Polio Eradication Initiative. Circulating vaccine-derived poliovirus, 2020. Available: http://polioeradication.org/polio-today/ polio-now/this-week/circulating-vaccine-derived-poliovirus/

36 Global Polio Eradication Initiative. Wild poliovirus list, 2020. Available: http://polioeradication.org/polio-today/polio-now/wildpoliovirus-list/

37 World Health Organization. Poliomyelitis fact sheet, 2019. Available: https://www.who.int/news-room/fact-sheets/detail/poliomyelitis

38 World Health Organization. Ground zero in guinea: the Ebola outbreak smoulders - undetected - for more than 3 months. Available: https://www.who.int/csr/disease/ebola/ebola-6-months/ guinea/en/

39 U.S. Centers for Disease Control and Prevention. 2014-2016 Ebola outbreak in West Africa, 2019. Available: https://www.cdc.gov/vhf/ ebola/history/2014-2016-outbreak/index.html

40 Garske T, Cori A, Ariyarajah A, et al. Heterogeneities in the case fatality ratio in the West African Ebola outbreak 2013-2016. Philos Trans R Soc Lond B Biol Sci 2017;372:20160308.

41 World Health Organization. Zika epidemiology update. World Health Organization, 2019.

42 Cunha AJLAda, de Magalhães-Barbosa MC, Lima-Setta F, et al. Microcephaly case fatality rate associated with Zika virus infection in Brazil: current estimates. Pediatr Infect Dis J 2017;36:528-30.

43 Barbi L, Coelho AVC, Alencar LCAde, et al. Prevalence of guillainbarré syndrome among Zika virus infected cases: a systematic review and meta-analysis. Braz J Infect Dis 2018;22:137-41.

44 World Health Organization. Yellow fever outbreak Angola, Democratic Republic of the Congo and Uganda 2016-2017. Available: http://www.who.int/emergencies/yellow-fever/en/

45 Ahmed QA, Memish ZA. Yellow fever from Angola and Congo: a storm gathers. Trop Doct 2017;47:92-6.

46 World Health Organization. Democratic Republic of the Congo Ebola outbreak. World Health Organization, 2018. https://www.who.int/ emergencies/diseases/ebola/drc-2018

47 World Health Organization. Ebola virus disease fact sheet, 2020. Available: https://www.who.int/news-room/fact-sheets/detail/ebolavirus-disease

48 Associated Press. China investigates respiratory illness outbreak sickening 27. KTAR News, 2019.

49 World Health Organization. Coronavirus disease (COVID-19) pandemic, 2020. Available: https://www.who.int/emergencies/ diseases/novel-coronavirus-2019 [Accessed 29 Apr 2020]. 